\title{
Updates of COVID-19
}

\section{Deepali Chittora $^{1}$ (D) $\cdot$ Bhanu Raj Meena ${ }^{1} \cdot$ Shivangi Mittholiya ${ }^{1} \cdot$ Kanika Sharma $^{1}$}

Received: 21 August 2020 / Accepted: 29 March 2021 / Published online: 3 May 2021

(C) Sociedade Brasileira de Engenharia Biomedica 2021

\begin{abstract}
Causal Organism COVID-19 is a disease caused by the novel coronavirus (SARS-CoV-2). Positive-sense ssRNA viruses are about $30 \mathrm{~kb}$ long. Coronaviruses have a broad spectrum of action and affect multiple organisms.

Origin of Disease The disease outbreak has been initiated in Wuhan, China, in December 2019. The disease has been originated from the wet animal market of Wuhan City, where a large number of peoples have come in contact with animals. It is known to infect the neurological, respiratory, enteric, and hepatic systems. SARSCoV-2 is highly infectious, and its outbreak is worldwide (national and international level) and becomes pandemic.

Control Presently, the number of cases continues to rise at a global level, and it is clear that these viruses pose a significant threat to public health. Consequently, extensive treatments, vaccines, and drugs have been developed by researchers to control the transmission of infection. This led to the isolation of patients that were administered a variety of treatments. Special attention and guidelines have been given by various government organizations to protect or reduce transmission between children, healthcare providers, and old-aged peoples.
\end{abstract}

Keywords Isolation · Health · Disease $\cdot$ Virus · Treatment · Worldwide

\section{Introduction}

Coronaviruses (CoVs) have been linked with major disease outbreaks in East Asia and the Middle East. They cause severe acute respiratory syndrome (SARS) and the Middle East respiratory syndromes (MERS). The disease has been found in 2002 and 2012. At present, a novel CoV has emerged in 2019-2020 which may cause a health hazard that specified the ongoing pandemic all over the world (RodriguezMorales et al. 2020). On 11 February 2020, the World Health Organization (WHO) announced the official designation for this current $\mathrm{CoV}$-associated disease to be "COVID19." These newly evolved CoVs have been posing a significant threat to global public health (Wellcome 2020).

COVID-19 is caused by a novel SARS-CoV-2 (severe acute respiratory syndrome coronavirus-2) reported in 2019 (Wang et al. 2020a, b, c). This virus has been originated from

Deepali Chittora

deepali25118@gmail.com

1 Microbial Research Laboratory, Department of Botany, University College of Science, Mohanlal Sukhadia University,

Udaipur, Rajasthan 313001, India a seafood market of Wuhan City, Hubei Province, China, on 12 December 2019, where a variety of wild and domestic animals are traded illegally (Dhama et al. 2014; Fehr and Perlman 2015; MacLachlan and Dubovi 2017; Ar Gouilh et al. 2018; Monchatre-Leroy et al. 2017; WHO 2003; Lu et al. 2020). Such markets can be considered as a critical place for the origin of this novel zoonotic disease and have enormous public health significance in the event of an outbreak. Coronaviruses have been spreaded from animals to humans, it is notion that the first person infected with the disease: a group mainly seller of the seafood market, he has been in contact with animals. A much larger number of coronaviruses have been detected in animals, particularly in bats, but have not been found in humans. Phylogenetic analysis of the structural genes has shown that 2019-nCoV is closer to bat SARSrelated $\mathrm{CoV}$. Therefore, SARS-CoV-2 might have originated from bats, while other hosts might have played a possible role in this disease transmission to humans (Chan et al. 2020). Due to this outstanding global outbreak, the WHO declared a "global health emergency" on 30 January 2020.

This virus has primarily targeted the human respiratory system. The clinical features of COVID-19 are varied, ranging from an asymptomatic state to acute respiratory distress syndrome and multi-organ dysfunction. The common clinical features include fever, cough, sore throat, fatigue, headache, 
myalgia, fatal respiratory infections in humans, conjunctivitis, and breathlessness (Kritas et al. 2020). Coronavirus infection has been also found in a wide variety of animals ranging from enteritis in cows and pigs and upper respiratory disease in chickens (Fehr and Perlman 2015). Thus, they are difficult to differentiate from other respiratory infections. In severe conditions, the disease can progress to pneumonia, respiratory failure, and death.

In the present situation, patients of COVID-19 continuously rise, and there is neither an official vaccine nor specific and effective antiviral drugs available to treat human $\mathrm{CoV}$ infection (Lu 2020; Sheahan et al. 2020, b; Pillaiyar et al. 2020a, b). Most of the countries have been working on the development of novel vaccines and efforts to prevent further spreading of this novel virus by employing preventive and control approaches. The repeated emergence and global scale of transmission, a significant number of deaths, infection and mortality of care providers and healthcare workers (HCWs), and a higher risk of death in susceptible groups have been the major causes of concern.

Several health workers, doctors, researchers, and pharmacists have been making an effort to develop potential drugs and vaccines at the national and international levels to control the severe effect of this disease outbreak (Li et al. 2020a, b, d).

\section{The scenario of COVID-19 outbreak}

Over the past two decades, the current emergence of COVID-19 is the third CoV outbreak in humans (Munster et al. 2020). It is no coincidence that Fan et al. 2019 predicted potential SARS or MERS-like CoV outbreaks in China following pathogen transmission from bats (Fan et al. 2019). The COVID-19 has been spreading rapidly throughout the country and subsequently to 70 other countries as the product of natural evolution; the findings are published in Nature Medicine. Due to the severity of this outbreak and the potential of spreading on an international scale, the WHO declared a "global health emergency" on 30 January 2020 (WHO 2020) (Table 1). At present, we are not in a position to effectively treat COVID-19 since neither approved vaccines nor specific antiviral drugs for treating human $\mathrm{CoV}$ infections are available ( $\mathrm{Lu} 2020$, b; Sheahan et al. 2020, b; Pillaiyar et al. 2020). Most nations are currently making efforts to prevent further spreading of this potentially deadly virus by implementing preventive and control strategies.

\section{Structure and classification of coronavirus}

Coronaviruses have a broad spectrum of action and affect multiple organisms (Weiss and Leibowitz, 2011; Li et al. 2020a, b, c, d). The recently emerging 2019-SARS-CoV-2 has caused havoc in China and threats to the global population. Recently, the International Committee on Taxonomy of Viruses (ICTV) has proposed to name it as "severe acute respiratory syndrome coronavirus 2" (SARS-CoV-2).

It is an enveloped virus particle. The diameter of the envelope is approximately $120 \mathrm{~nm}$. An envelope is surrounded with club-shaped glycoproteins that gives the viruses a crown-like or coronal appearance under the electron microscope. The nucleocapsid of the virus is made up of a protein and nucleic acid; it may be helical or tubular. The protein component that covers the nucleic acid is known as a capsid. The nucleic acid of coronavirus is a single-strand positivesense RNA. The family Coronaviridae is usually considered to contain two genera, Coronavirus and Torovirus, both differ in their nucleocapsid morphology, the former being helical and the latter being tubular. Coronavirus is the main agent of gastrointestinal disease in humans, bovines (Zhang et al. 1994; Gomez et al. 2017; Kim et al. 2004), poultry, etc. The SARS coronavirus can cause a highly communicable respiratory disease in humans (Luo et al. 2020).

Next generation sequencing and phylogenetic analysis of the 2019-nCoV genome have revealed that sequences are $88 \%$ identical to bat-derived SARS-like coronaviruses outbreak in 2003, more distant from SARS-CoV by $79 \%$ and MERS-CoV by $50 \%$ ( $\mathrm{Lu}$ et al. 2020).

Structural analysis suggested that $2019-\mathrm{nCoV}$ might be able to bind receptor angiotensin-converting enzyme 2 in humans; this is similar to SARS-CoV which was confirmed by Zhou et al. (2020). The novel coronavirus 2019 belongs to the genus Betacoronavirus, subgenus Sarbecovirus, and family Coronaviridae. The family Coronaviridae possesses a single-strand, positive-sense RNA genome ranging from 26 to $32 \mathrm{~kb}$ in length (Su et al. 2016). Coronaviridae is subdivided into subfamily Orthocoronavirinae, order Nidovirales, and four genera such as Alphacoronavirus, Betacoronavirus, Gammacoronavirus, and Deltacoronavirus. There are four species of coronaviruses, namely HKU1, NL63, 229E, and OC43, which cause mild respiratory disease. The genera Alphacoronavirus and Betacoronavirus originate from bats, while the Gammacoronavirus and Deltacoronavirus have evolved from birds and swine gene pools ( $\mathrm{Li}$ et al. 2020a, b, c, d; Lai and Holmes 2001; Woo et al. 2012).

\section{Virus genome analysis and annotation}

Reference sequence of the genome of coronavirus was obtained from GenBank using Blastn with 2019-nCoV as a query. The open reading frames of the verified genome sequences were predicted using Geneious (version 11.1.5) and annotated using the conserved domain database. Pairwise sequence identities have also been calculated using Geneious. Potential genetic 
Table 1 Events of COVID-19

Date Finding

December 2019

8 December 2019

12 December 2019

31 December 2019

3 January 2020

7 January 2020

9 January 2020

12 January 2020

13 January 2020

15 January 2020

20 January 2020

22 January 2020

23 January 2020

25 January 2020

30 January 2020

11 February 2020

3 March 2020

4 March 2020

5 March 2020

11 March 2020

8 August 2020

20 December 2020
The virus was originated in bats and transmitted to humans through yet unknown intermediary animals in Wuhan, Hubei Province, China

Infection was found in China

Reported that infection was due to outbreak of novel CoV (originally named 2019-nCoV) that was first identified in Wuhan City, Hubei Province, China

The Wuhan Municipal Health Commission announced 27 cases of pneumonia of unknown etiology were identified in China

31 December 2019 through 3 January 2020, a total of 44 case-patients with pneumonia of unknown etiology were reported to WHO by the national authorities in China. During this reported period, the causal agent was not identified

The causative organism was identified from throat swab samples conducted by the Chinese Centre for Disease Control and Prevention (CCDC) and was afterward named severe acute respiratory syndrome coronavirus 2 (SARS-CoV-2)

A novel coronavirus, 2019-nCoV, was officially identified as the cause of an outbreak of viral pneumonia in Wuhan, China

China shared the genetic sequence of the novel coronavirus to different countries for use in developing specific diagnostic kits

The Ministry of Public Health, Thailand, reported the first imported case of lab-confirmed novel coronavirus (2019-nCoV) from Wuhan, Hubei Province, China

The Ministry of Health, Labour and Welfare, Japan (MHLW), reported an imported case of laboratory-confirmed 2019-novel coronavirus (2019-nCoV) from Wuhan, Hubei Province, China

National IHR Focal Point (NFP) for Republic of Korea reported the first case of novel coronavirus in the Republic of Korea Real-time tentative assessment of the epidemiological characteristics of novel coronavirus infections in Wuhan, China

The epicenter in Wuhan is quarantined comprised of an urban area spanning $1528 \mathrm{~km}^{2}$ and exceeds 11 million residents At least 1975 cases had been reported since the first patient was hospitalized on 12 December 2019

First confirmed case of nCoV in India was diagnosed on 30 January 2020. The WHO declared the Chinese outbreak of COVID-19 to be a public health emergency of international concern posing a high risk to countries with vulnerable health systems. The emergency committee has stated that the spread of COVID-19 may be interrupted by early detection, isolation, prompt treatment, and the implementation of a robust system to trace contacts

The disease was named COVID-19 by the World Health Organization (WHO)

A total of 3112 deaths have been reported worldwide. Outside of China, 166 of these deaths have been reported in the Philippines, Japan, Korea, Italy, France, Iran, Australia, Thailand, and the USA

A total of 16,659 tests for COVID-19 have been conducted across the UK. To date, 85 individuals have tested positive resulting in the UK public health risk for viral infection being raised from low to moderate (Public Health England, Coronavirus (COVID-19), 2020). To prevent transmission, the UK government is following direct guidelines from the Department of Health $(\mathrm{DoH})$ for encountering overseas travelers with respiratory infections, particularly for those who have traveled to Wuhan (HM Government, 2020, WHO, 2020)

Around 96,000 reported cases of COVID-2019 and 3300 reported deaths in world

The WHO announced that the outbreak should be considered a pandemicRead more: https://www.newscientist. com/term/covid-19/\#ixzz6IL8DFQdN

According to Situation reports August 2020, World Health Organization (WHO): 1,8 6,14, 177 globel level confirmed cases and 7,02642 confirmeddeaths have been found all around the world

At global level there have been 75,110,651 confirmed cases of COVID-19, including 1,680,395 deaths, reported to WHO recombination has been investigated using SimPlot software (version 3.5.1) and phylogenetic analysis (Tables 2, 3, and 4).

\section{Phylogenetic analysis}

Alignment of 2019-nCoV sequence with reference sequences has been done with MAFFT software (version 7.450). Phylogenetic analyses of the complete genome and major coding regions have RAxML software (version 8.2.9) with
1000 bootstrap replicates, employing the general timereversible nucleotide substitution model.

\section{Current diagnostic tools for COVID-19}

Presently, several diagnostic tests for identification of infection of coronavirus include RT-PCR, real-time reverse transcription PCR (rRT-PCR), and reverse transcription loopmediated isothermal amplification, and real-time RT-LAMP has been performed (Chan et al. 2015; Wu et al. 2020). RT- 
Table 2 Genome of coronavirus

1. Positive-sense ssRNA viruses is about $30 \mathrm{~kb}$ long, with a $\mathrm{G}+\mathrm{C}$ content of $38 \%$, enclosed by a $5^{\prime}$-cap and 3 '-poly-A tail, and it codes for a large polyprotein

2. Polyprotein is cleaved by viral-encoded proteases to form the following:

$\checkmark$ RNA-dependent RNA polymerase

$\checkmark$ ATPase helicase

3. 6 ORFs (open reading frame)

4. Genetic recombination: if 2 viruses infect the same cell at the same time

5. Group II coronaviruses have the following surface protein:

$\checkmark$ The large surface glycoprotein (S protein) that forms the petal-shaped surface projections

$\checkmark$ A small envelope protein (E protein)

$\checkmark$ A membrane glycoprotein (M protein)

$\checkmark$ A nucleocapsid protein (N protein) that forms a complex with the RNA

$\checkmark$ A surface hemagglutinin-esterase protein present on OC43

6. Receptors for viral protein:

$\checkmark$ Group I coronaviruses $229 \mathrm{E}$ use human aminopeptidase $\mathrm{N}$ as their cellular receptor

$\checkmark$ Mouse hepatitis virus, a group II coronavirus, uses a member of the carcinoembryonic antigen family as its receptor

$\checkmark$ The receptor for OC43 is not known, but it may be 1 of several cell surface molecules, including 9-O-acetylated neuraminic acid and HLA-I molecule

$\checkmark$ The SARS coronavirus uses angiotensin-converting enzyme II as its cellular receptor

$\checkmark$ Structurally, the SARS coronavirus (SARS-CoV) has a well-defined composition comprising 14 binding residues that directly interact with human angiotensin-converting enzyme 2

LAMP has been used to detect MERS-CoV; it is highly specific and has a similar sensitivity to rRT-PCR (Lee et al. 2016; Huang et al. 2018).

The China National Health Commission (CNHC) laboratory examinations established that nasopharyngeal and oropharyngeal swab tests have become a standard assessment for the diagnosis of COVID-19 infection (Chu et al. 2020). Two-/one-step quantitative RT-PCR (qRT-PCR) assays were developed to detect two different regions (ORF1b and N) of the SARS-CoV-2 genome, allowing identifying patients earlier (Chu et al. 2020). Later, three novel RT-PCR assays targeting the RNA-dependent RNA polymerase (RdRp)/ helicase (Hel), spike (S), and nucleocapsid (N) genes of SARS-CoV-2 were developed. Among them, the COVID$19-\mathrm{RdRp} / \mathrm{Hel}$ assay had the lowest limit of detection in vitro (Chan et al. 2020a, b).

\section{Symptom and diagnosis}

The mode of disease transmission is inhalation or contact with infected droplets. The incubation period ranges from 2 to 14 days. Older people are more likely to develop serious illnesses because they have other diseases like cardiovascular disease, diabetes, chronic respiratory disease, and cancer. The main symptom of the disease is characterized by fever, dry cough, runny nose, tiredness, and muscle ache, often with progressive difficulty in breathing (Huang et al. 2020a, b; Chen et al. 2020). The disease is mild in most people; in some (usually the elderly and those with comorbidities), it may progress to pneumonia, acute respiratory distress syndrome (ARDS), and multi-organ dysfunction. Many people are asymptomatic. This case fatality rate is estimated to range from 2 to $3 \%$. Diagnosis is the demonstration of the virus in

Table 3 List of software used in the analysis of sequence of the coronavirus genome

\begin{tabular}{ll}
\hline Software & Function \\
\hline $\begin{array}{l}\text { OLIGO Primer Analysis Software } \\
\text { version 6.44 }\end{array}$ & $\begin{array}{c}\text { Primers were designed with use of OLIGO Primer Analysis Software version 6.44 on the basis of the assembled } \\
\text { partial genome and were verified by Primer-Blast }\end{array}$ \\
$\begin{array}{ll}\text { CLC Bio software version 11.0.1. } \\
\text { Genome alignments and sequence illustrations were generated with CLCBio software } \\
\text { The open reading frames of the verified genome sequences were predicted using Geneious (version 11.1.5) and } \\
\text { annotated using the Conserved Domain Database. Pairwise sequence identities were also calculated using } \\
\text { Geneious }\end{array}$ \\
$\begin{array}{l}\text { Potential genetic recombination was investigated using SimPlot software (version 3.5.1) and phylogenetic analysis } \\
\text { MAFFT software (version 7.450) }\end{array}$ & $\begin{array}{c}\text { Sequence alignment of 2019-nCoV with reference sequences was done with MAFFT software (version 7.450) } \\
\text { RAxML software (version 8.2.9) }\end{array}$ \\
$\begin{array}{c}\text { Phylogenetic analyses of the complete genome and major coding regions were done with RAxML software } \\
\text { (version 8.2.9) }\end{array}$ \\
\hline
\end{tabular}


Table 4 Pharmaceutical companies and research institutes involved in developing coronavirus drugs/vaccines

Company Method

Entos Pharmaceuticals

Altimmune (USA)

Inovio Pharmaceuticals has collaborated with Beijing Advaccine Biotechnology Company, China

Algernon Pharmaceuticals

University of British Columbia and APEIRON Biologics

Moderna Massachusetts contribution with Vaccine Research Center and unit of the National Institute of Allergy and Infectious Diseases (NIAID)

MIGAL Research Institute contribution with Volcani Institute

Tonix Pharmaceuticals has joined with Southern Research

Innovation Pharmaceuticals

Clover Biopharmaceuticals

CytoDyn

Applied DNA Sciences contribution with LineaRx and Takis Biotech BIOXYTRAN

Inovio in partnership with Gene One Life Science

BioCryst Pharmaceuticals

Synairgen Research

Bharat Biotech, Hyderabad, collaborated with the virologists of the University of Wisconsin-Madison and vaccine company FluGen

BioNTech partnered with Pfizer and also working with Fosun Pharma in China

Gilead Science pharmaceutical company

Fujifilm Toyama Chemical's (Tokyo, Japan)

FiercePharmaAsia
Fusogenix (proteolipid) DNA vaccine stimulates an immune response within the body to stop COVID-19 infections

Developed an intranasal COVID-19 vaccine

Testing under preclinical trials

INO-4800, as a completely unique coronavirus vaccine. Ready for clinical trials at the end of April

NP-120 (ifenprodil) is an N-methyl-d-aspartate (NDMA) receptor and glutamate receptor antagonist sold under the brand Cerocal

APN01 has been tested in China

APN01 (nonimmune oncology product) is a recombinant enzyme of the Renin-angiotensin system tested for treatment of COVID-19

mRNA-1273 vaccine targets the Spike (S) protein of the coronavirus. This is an effective vaccine to prevent infection with SARS-CoV-2 which is an urgent public health priority

Bronchitis virus (IBV) vaccine to treat avian coronavirus has been modified to treat COVID-19

TNX-1800 vaccine is a modified horsepox virus vector. It expresses a protein derived from the virus that causes the coronavirus infection

Brilacidin, a defensin mimetic drug candidate. This drug has shown antibacterial, anti-inflammatory, and immunomodulatory properties in several clinical trials

Developed a highly purified type of the S-Trimer vaccine to be available for performing preclinical studies

Leronlimab (PRO 140) is a CCR5 antagonist, used as a potential coronavirus drug

Developed a linear DNA vaccine using PCR technology

BX-25 for treatment of acute respiratory distress syndrome (ARDS) in the last stage of coronavirus-infected patients

DNA immunotherapy, INO-4700 (GLS-5300)

Galidesivir (BCX4430) has a broad-spectrum activity against coronavirus. It is an RNA polymerase inhibitor that disrupts the method of viral replication

SNG001 (inhaled drug) is a formulation of naturally occurring interferon- $\beta$, which is administered directly to the lungs to decrease the severity

CoroFlu is a one-drop COVID-19 nasal vaccine built on a flu vaccine "backbone" that has been shown to be safe and well-tolerated in humans, in phase I and phase II clinical trials

mRNA-based vaccine (BNT162) intends to prevent the SARS-CoV-2 Coronavirus from causing COVID-19 disease in humans

Rapidly assess the safety and efficacy of Remdesivir as a potential treatment for COVID-19 through several ongoing clinical trials. This antiviral drug gained emergency use authorization (EUA) from the FDA on 1 May 2020, based on preliminary data showing a faster time to the recovery of a hospitalized patient with severe disease

Develop a favilavir drug (label as Avigan), which is effective for the treatment of influenza in Japan and China because it inhibits the RNA-dependent RNA polymerase. Currently, the National Medical Products Administration of China has approved favilavir for treating COVID-19 in China. Despite its potential, the US Food and Drug Administration (FDA) has not yet regarded favilavir as an effective treatment medicine for coronavirus

Developed chloroquine for the treatment of novel coronavirus infection. The result failed in China, but still Donald Trump's shows confidence around this malaria drug chloroquine. The FDA has lifted an import alert on India's Ipca Laboratories so that it can send chloroquine to the USA, but 
Table 4 (continued)

Company Method

the Indian government has decided that no such drug should leave its border

Jenner Institute and Oxford Vaccine Group at the University of Oxford

ChAdOx $1 \mathrm{nCoV}-19$ is a potential vaccine against COVID-19. The vaccine uses a weakened version of chimpanzee adenovirus as vector, infused with the genetic material of SARS-CoV-2 spike protein. Adenovirus causes common cold. After vaccination, the SARS-CoV-2 surface spike protein is produced, which alerts the immune system to attack COVID-19

respiratory secretions by special molecular tests. Common laboratory findings include low white blood cell counts with elevated C-reactive protein (CRP). The computerized tomographic chest scan is usually abnormal even in those with no symptoms or mild disease. Treatment is essentially supportive; the role of antiviral agents is yet to be established. Prevention entails home isolation of suspected cases and those with mild illnesses and strict infection control measures at hospitals that include contact and droplet precautions. The virus spreads faster than its two ancestors, the SARS-CoV and Middle East respiratory syndrome coronavirus (MERS$\mathrm{CoV}$ ), but has lower fatality (Elsevier, Novel Coronavirus Information Center 2020).

Once symptoms have developed, a person's viral load declines steadily, and they become increasingly less infectious. However, people appear to keep shedding the virus for around 2 weeks after they recover from COVID-19, both in their saliva and stools. This means that even once a person's symptoms have cleared, it may still be possible to infect other people (Jin et al. 2020).

People with mild or no symptoms can have a very high viral load in their upper respiratory tracts, meaning they can shed the virus through spitting, touching their mouths or noses and then a surface, or possibly talking. The new coronavirus has also been found to persist for days on surfaces, though that does not necessarily mean these virus particles could still infect other people. That could be diminished by ultraviolet light, heat, or humidity (Liu and Liu 2019).

\section{Coronavirus treatment: vaccines/drugs for COVID-19}

Since at this time, no approved treatments to cure MERS and SARS-CoV infection (Adedeji et al. 2013; Falzarano et al. 2013; Lu et al. 2013; Dhama et al. 2020). Prevention is critical because of the different properties of this virus that is:

- Nonspecific features of the disease

- The infectivity even before the inception of symptoms in the incubation period

- Communication from an asymptomatic person
- Long incubation time, tropism for mucosal surfaces such as the conjunctiva

- Prolonged duration of the infection and transmission even after clinical recovery

Presently, no successful and licensed treatment is available; first therapeutic drugs that might be effective in managing COVID-19 include remdesivir, lopinavir/ritonavir alone or in combination with interferon- $\beta$, convalescent plasma, and mAbs (Li et al. 2020a, b, c, d).

However, a number of researchers are working in multiple centers to control the outbreak of disease. Controlled clinical trial is currently in progress to assess the efficacy and safety of patients infected with COVID-19. Initial treatment of fever includes antipyretic drugs such as paracetamol, while expectorants such as guaifenesin may be used for a dry cough (Wang et al. 2020a, b, c). Severe conditions such as acute respiratory infection, respiratory distress, hypoxemia, or shock require the administration of immediate oxygen therapy. This should be at $5 \mathrm{~L} / \mathrm{min}$ to reach $\mathrm{SpO} 2$ targets of $\geq 90 \%$ in nonpregnant adults and children and $\geq 92-95 \%$ in pregnant women (Rosjo et al. 2011; WHO 2013, WHO 2014).

In the absence of shock, intravenous solutions should be carefully administered (Schultz et al. 2017). Renal replacement therapy (RRT) must be given for patients with an acute kidney injury (Wang et al. 2020a, b, c). If a patient can develop a fungal and bacterial infection, antibiotic therapy should be given within $1 \mathrm{~h}$, for assessment for sepsis (Rhodes et al. 2016). Therefore, conventional and balanced antibiotic treatment must still be followed (Kui et al. 2020).

Various drugs such as IFN- $\alpha$ and lopinavir/ritonavir; oseltamivir, a neuraminidase inhibitor; and glucocorticoids have been recommended by the National Health Commission of the People's Republic of China. These drugs have enhanced the immunity of COVID-19-infected patients (Chu 2004). In children, methylprednisolone should be limited to $1-2 \mathrm{mg} / \mathrm{kg} /$ day for a maximum of 5 days (Wang et al. 2020a, b, c; Kui et al. 2020). Furthermore, the chloroquine phosphate function might be effective in increasing endosome $\mathrm{pH}$ and preventing virus fusion in the host cell (Gao et al. 2020). Recently, the blocking of the virus attachment to 
ACE-2 receptors and the employment of convalescent plasma therapy seem to be useful in treatment (Zhang et al. 2020).

According to the Epidemiology Unit Ministry of Health \& Indigenous Medical Services, some important guidelines for home quarantine must be followed:

- Isolation of confirmed or suspected cases with mild illness at home is recommended. Household members should stay in a separate room.

- The ventilation at home should be good with sunlight to allow for the destruction of the virus.

- Patients should be asked to wear a simple surgical mask and practice cough hygiene.

- The European Centre for Disease Prevention and Control (ECDC) also published the information leaflet to peoples; i.e., avoid contact with sick people, in particular those with a cough.

- Wash your hands with soap and water or use an alcoholbased disinfectant solution before eating, after using the toilet, and after any contact with animals.

- Maintain at least 1-m distance from family and other members.

- Other family members should use a separate bathroom. If sharing the same bathroom, cleaning of taps, doorknobs, and utensils with soap and water is a requirement.

- Minimize guests to the house; the patient should not interact with any visitors.

- Frequent handwashing with soap and water for at least $20 \mathrm{~s}$ at a time and maintain alcohol-based hand hygiene in instances where handwashing facilities are inadequate.

- Avoid touching the eyes, nose, and mouth with an unwashed hand.

- The home-quarantined person is expected to monitor body temperature using a thermometer twice a day. If he/she develops fever, cough, difficulty in breathing, sore throat, body aches, and pain, including flu-like symptoms, immediately inform the medical officer of health of the area.

- After use, disposable facemasks and gloves should be properly discarded without reuse, preferably in a closed container.

- Assign separate dishes, drinking glasses, cups, eating utensils, towels, bedding, and other items for the quarantined person.

- Used utensils, bed covering, and clothes should be washed with soap and water.

\section{The vaccine testing process}

According to the data from August 2020, about 165 vaccines are in development and process and 28 vaccines have reached the stage of human trials. The development and testing of vaccines need many years of research before reaching the clinic and market. Several scientists are continuously working day by day and racing to produce a safe and effective vaccine for controlling the outbreak of coronavirus by the next year.

This work began in January with the interpreting of the SARS-CoV-2 genome. The first vaccine safety trials on humans have been started in March, but their results are in doubt. Several trials are failing, and other trials may stop without a clear result. A few may succeed in stimulating the immune system to produce effective antibodies against the virus. All vaccine development processes start through preclinical trial including phase I, phase II, and phase III; approval; and combined phases. Scientists give the vaccine to animals such as mice or monkeys in the preclinical test. The preclinical phase includes 3 phases. In phase I trial, scientists give the vaccine to a small number of people to test safety and dosage as well as to confirm that it stimulates the immune system. In phase II trial, scientists give the vaccine to hundreds of people split into groups, such as children and the elderly, to see if the vaccine acts differently in them. These trials further test the vaccine's safety and ability to stimulate the immune system. In phase III trial, scientists give the vaccine to thousands of people and wait to see how many become infected, compared with volunteers who received a placebo. These trials can determine the vaccine protects against the coronavirus. In June, the FDA said that a coronavirus vaccine would have to protect at least $50 \%$ of vaccinated people to be considered effective. The last approval regulators in each country have reviewed the trial results and decide whether to approve the vaccine or not. During a pandemic, a vaccine may receive emergency use authorization before getting formal approval. Another way to accelerate vaccine development is to combine the phases. Some coronavirus vaccines are now in phase I/II trials, for example, in which they are tested for the first time on hundreds of people (Fig. 1).

At present, various companies have been continuously developing vaccines and reaching for trials on humans, along with a selection of promising vaccines still being tested in cells or animals.

Moderna develops vaccines based on messenger RNA (mRNA) to produce viral proteins in the body. They have yet to bring one to the market. In partnership with National Institutes of Health, they found that the vaccine protects monkeys from the coronavirus. In March, the company put the first COVID-19 vaccine into human trials, which yielded promising results; after carrying out phase II study, they launched a phase III trial on 27 July 2020. The final trial will enroll 30,000 healthy people at about 89 sites around the USA. The government has bankrolled Moderna's efforts with nearly $\$ 1$ billion in support.

The German company BioNTech has entered into collaborations with Pfizer, based in New York, and the Chinese drugmaker Fosun Pharma to develop their mRNA-based vaccine. In July, they posted preliminary results from their phase 
Fig. 1 Stages of vaccine testing process
The Vaccine Testing Process

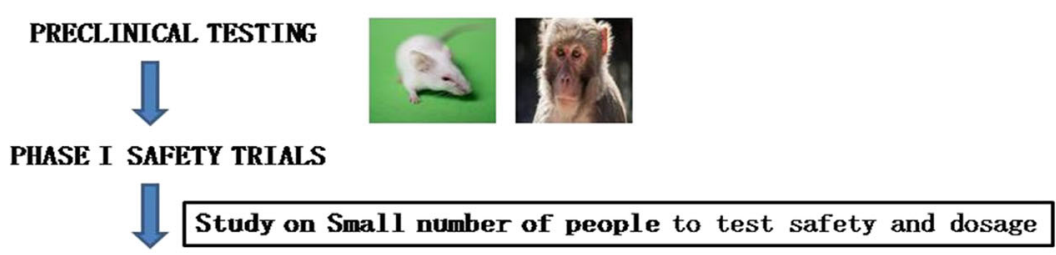

PHASE II EXPANIED TRIALS

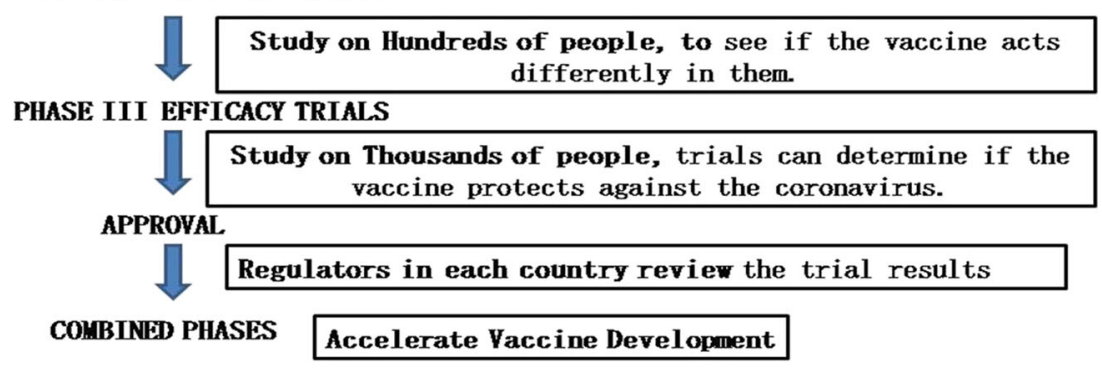

I/II trials in the USA and Germany. They found that the volunteers produced antibodies against SARS-CoV-2, as well as immune cells called $\mathrm{T}$ cells that respond to the virus. Some volunteers experienced moderate side effects such as sleep disturbances and sore arms. On 27 July 2020, they announced to launch phase II/III trial with 30,000 volunteers in the USA and other countries including Argentina, Brazil, and Germany.

The Trump US administration awarded a $\$ 1.9$ billion contract for 100 million doses to be delivered by December 2020 and the option to acquire 500 million more doses. Meanwhile, Japan made a deal for 120 million doses. If approved, Pfizer said they expect to manufacture over 1.3 billion doses of their vaccine worldwide by the end of 2021.

Imperial College London researchers have developed a "self-amplifying" RNA vaccine, which boosts the production of a viral protein to stimulate the immune system. They began phase I/II trials on June 15 and have partnered with Morningside Ventures to manufacture and distribute the vaccine through a new company called VacEquity Global Health. The researchers expect to know if the vaccine is effective by the end of the year.

Indian vaccine-maker Zydus Cadila has created a DNAbased vaccine. On July 3 , they announced the approval to start human trials, becoming the second company in India to enter the COVID-19 vaccine race after Bharat Biotech. After a successful phase I trial, they entered phase II on August 6.

On June 30, the Japanese biotechnology company AnGes announced they had started safety trials on a DNA-based vaccine and developed in partnership with Osaka University and Takara Bio.

The California-based company Arcturus Therapeutics and Duke-NUS Medical School in Singapore have developed an mRNA vaccine. The "self-replicating" design of the molecules in the vaccine led to strong immune responses in animal experiments. On July 21, Singapore approved their application for a phase I/II trial in humans.

On 30 June 2020, the American company Inovio announced they had interim phase I data on their DNA-based vaccine. They found no serious adverse effects and measured an immune response in 34 out of 36 volunteers. They plan to start phase II/III trials.

In March 2020, the Trump administration unsuccessfully tried to entice CureVac to move its research from Germany to the USA. In June 2020, the company launched phase I trials of its mRNA vaccine. The company said its German facility can make hundreds of millions of vaccine doses a year.

The Korean company Genexine started testing the safety of a DNA-based vaccine in June 2020. They anticipate moving to phase II trials in the fall.

In June 2020, Chinese researchers at the Academy of Military Medical Sciences, Suzhou Abogen Biosciences, and Walvax Biotechnology announced they would start their country's first safety trials on an mRNA-based vaccine, called ARCoV. Earlier studies on monkeys reportedly showed protective effects.

The French pharmaceutical company Sanofi is developing an mRNA vaccine in partnership with Translate Bio. On 23 June 2020, they announced they were planning phase I trials in the fall.

A vaccine in development by the British-Swedish company AstraZeneca and the University of Oxford is based on a chimpanzee adenovirus called ChAdOx1. A study on monkeys found that the vaccine provided them protection. In May, the USA awarded the project $\$ 1.2$ billion in support. Their phase I/II trial reported that the vaccine was safe, causing no severe side effects. It raised antibodies against the coronavirus as well as other immune defenses. The vaccine is now in phase II/III 
trials in England and India, as well as phase III trials in Brazil and South Africa. The project may deliver emergency vaccines by October. AstraZeneca has said their total manufacturing capacity for the vaccine, if approved, stands at two billion doses. India's Serum Institute has already produced millions of doses to be used in trials.

The Chinese company CanSino Biologics developed a vaccine based on an adenovirus called Ad5, in partnership with the Institute of Biology at the country's Academy of Military Medical Sciences. In May, they published promising results from a phase I safety trial, and in July, they reported that their phase II trials demonstrated the vaccine produced a strong immune response. In an unprecedented move, the Chinese military approved the vaccine on June 25 for a year as a "specially needed drug." CanSino would not say whether vaccination would be mandatory or optional for soldiers.

Researchers at Beth Israel Deaconess Medical Center in Boston developed a method for making vaccines out of a virus called Adenovirus 26, or Ad26 for short. Johnson \& Johnson developed vaccines for Ebola and other diseases with Ad26 and now made one vaccine for the coronavirus. In March, they received \$456 million from the US government to support their move towards production. The vaccine has provided protection in experiments on monkeys. Johnson \& Johnson launched phase I/II trials in July and planning for phase III trials in September. In August, the federal government agreed to pay $\$ 1$ billion for 100 million doses if the vaccine is approved. The company is aiming for a production of at least a billion doses in 2021 .

Gamaleya Research Institute, part of Russia's Ministry of Health, launched a phase I trial in June of a vaccine they call Gam-COVID-Vac-Lyo. It is a combination of two adenoviruses, Ad5 and Ad26, both engineered with a coronavirus gene. In July, the chair of the upper house of Russia's Parliament announced the country may start vaccine production by the end of the year.

The Swiss company Novartis will manufacture a vaccine based on a gene therapy treatment developed by the Massachusetts Eye and Ear Hospital. A virus called an adeno-associated virus delivers coronavirus gene fragments into cells. Phase I trials are set to begin in late 2020.

The American company Merck announced in May it would develop a vaccine from vesicular stomatitis viruses, the same approach it successfully used to produce the first approved vaccine for Ebola. The company is partnering with IAVI and has received \$38 million in support from the US government. Unlike most other vaccines, this one could be taken orally.

After acquiring the Austrian firm Themis Bioscience in June, Merck developed a second vaccine. It uses a weakened measles virus to carry genetic material into patients' cells. Merck says it will start clinical trials in the third quarter of 2020.
Vaxart's vaccine is an oral tablet containing an adenovirus that delivers coronavirus genes. They are preparing for phase I trials.

\section{Protein-based vaccines}

Protein-based vaccines use a coronavirus protein or a protein fragment to provoke an immune response.

In July, the Chinese company Anhui Zhifei Longcom began phase II trials for a vaccine that is a combination of viral proteins and an adjuvant that stimulates the immune system. The company is part of Chongqing Zhifei Biological Products and has partnered with the Chinese Academy of Medical Sciences.

Maryland-based Novavax has developed a way to stick proteins onto microscopic particles. They have created vaccines for a number of different diseases using this platform; their flu vaccine finished phase III trials in March. The company launched trials for a COVID-19 vaccine in May, and the Coalition for Epidemic Preparedness Innovations has invested $\$ 384$ million in the vaccine. In July, the US government awarded $\$ 1.6$ billion to support the vaccine's clinical trials and manufacturing. If the trials succeed, Novavax expects to deliver 100 million doses for use in the USA by the first quarter of 2021. Plants in Europe and Asia would be able to satisfy more of the world's demand. On August 4, Novavax announced promising results from two preliminary studies in monkeys and humans.

Clover Biopharmaceuticals has developed a vaccine containing a protein from coronaviruses. The main objective of this vaccine is to stimulate the immune system. The vaccine is being given in conjunction with the so-called adjuvants made by British drugmaker GSK and the American company Dynavax. Investments from CEPI will support the development of manufacturing that could lead to the production of hundreds of millions of doses a year.

The Australian company Vaxine developed a vaccine that combines viral proteins with an adjuvant that stimulates the immune system. They successfully completed phase I trials in July and expect to start phase II trials in September.

Canada-based Medicago, partly funded by the cigarette maker Philip Morris, uses a species of tobacco to make vaccines. They deliver virus genes into leaves and the plant cells then create protein shells that mimic viruses. In July, Medicago launched phase I trials on a plant-based COVID19 vaccine in combination with adjuvants from drug makers GSK and Dynavax. If the trial goes well, they plan to start phase II/III trials in October.

A vaccine from Australia's University of Queensland delivers viral proteins altered to draw a stronger immune response. The university launched phase I trials in July, combining the proteins with an adjuvant made by CSL. If the 
results are positive, CSL will advance late-stage clinical trials and expects to make tens of millions of doses.

A second tobacco-based vaccine is in development at Kentucky BioProcessing, an American subsidiary of British American Tobacco, the maker of Lucky Strike and other cigarettes. Like Medicago, Kentucky BioProcessing engineers a species of tobacco called Nicotiana benthamiana to make viral proteins. The company previously used this technique to make a drug called ZMapp for Ebola. After preclinical testing in the spring, they registered a phase I trial for their coronavirus vaccine in July.

Taiwan-based vaccine-maker Medigen is making a vaccine made of a combination of spike proteins and an adjuvant from Dynavax. They have registered a phase I trial set to start in September.

After the SARS epidemic in 2002, Baylor College of Medicine researchers began developing a vaccine that could prevent a new outbreak. SARS and COVID-19 are very similar, and the researchers are reviving the project in partnership with the Texas Children's Hospital.

A vaccine in development by the University of Pittsburgh, called PittCoVacc, is a skin patch tipped with 400 tiny needles made of sugar. When placed on the skin, the needles dissolve and deliver virus proteins into the body.

In addition to their mRNA vaccine, Sanofi is developing a vaccine that is based on viral proteins. They are producing the proteins with engineered viruses that grow inside insect cells. GSK will supplement these proteins with adjuvants that stimulate the immune system. The companies expect to enter clinical trials in September. In July, they reached two major agreements for supplying the vaccine next year. They reached an agreement with the British government to provide up to 60 million doses if the vaccine succeeds in trials. Meanwhile, the USA will give the companies $\$ 2.1$ billion for 100 million doses. Sanofi has said it could potentially produce at least 600 million doses a year.

\section{Whole-virus vaccines}

Inactivated virus vaccine has been safe and provoked an immune response; the state-owned Chinese company Sinopharm launched phase III trials in July in the United Arab Emirates. Abu Dhabi's health minister has the first volunteer to be injected, and 15,000 people participated. In July, the chairman of Sinopharm told Chinese state media that the vaccine could be ready for public use by the end of the year.

The private Chinese company Sinovac Biotech is testing an inactivated vaccine called CoronaVac. In June, the company announced phase I/II trials on 743 volunteers and found no severe adverse effects and produced an immune response. Sinovac then launched a phase III trial in Brazil in July. The company is also building a facility to manufacture up to 100 million doses annually.
Researchers at the Institute of Medical Biology at the Chinese Academy of Medical Sciences, which has invented vaccines for polio and hepatitis A, started a phase II trial of an inactivated virus vaccine in June.

In collaboration with the Indian Council of Medical Research and the National Institute of Virology, the Indian company Bharat Biotech designed a vaccine called Covaxin based on an inactivated form of the coronavirus. When the company launched phase I/II trials in July, reports circulated that the vaccine would be ready by August 15 .

On July 18, North Korea's State Commission of Science and Technology announced on their website that they had started clinical trials on a vaccine based on part of the coronavirus spike protein. It is hard to independently determine how much truth there is in the claim from the isolated dictatorship. The commission claimed to have tested the vaccine on animals but provided no data. What's more, it stated that effectiveness trials would have to be carried out in another country "since there is no case of Covid-19 in DPR Korea." That is a claim outside experts find highly doubtful.

The Bacillus Calmette-Guerin vaccine has been developed in the early 1900s as a protection against tuberculosis. The Murdoch Children's Research Institute in Australia is conducting a phase III trial, and several other trials are underway to see if the vaccine partly protects against the coronavirus.

As of August 1, TASS Russian News Agency reported that human trials of the Gam-COVID-Vac-Lyo the vaccine candidate from the Gamaleya Scientific Research Institute are now complete. The process of registering the vaccine will begin as early as August 10 to 12 . The vaccine will then be made available "within three to seven days of registration," as per a Bloomberg report.

TASS reports that the head of the Russian Direct Investment Fund (RDIF) Kirill Dmitriev said the people who were injected with Gam-COVID-Vac-Lyo have developed immunity on the 21st day after receiving the first dose. He said that their immunity has doubled after they received the second injection.

There are currently more than 50 COVID-19 vaccine candidates in trials. The World Health Organization is working in collaboration with scientists, businesses, and global health organizations through the ACT accelerator to speed up the pandemic response. When a safe and effective vaccine is found, COVAX (led by WHO, GAVI, and CEPI) will facilitate the equitable access and distribution of these vaccines to protect people of countries. People most at risk will be prioritized. While we work towards rolling out a safe and effective vaccine fairly, we must continue the essential public health actions to suppress transmission and reduce mortality.

According to the WHO report on 18 December 2020, the FDA has formally authorized Moderna's COVID-19 vaccine for use in adults. Moderna expects to begin shipping 5.9 
million doses of the vaccine across the USA within days. More than 150 coronavirus vaccines are in development across the world, and hopes are high to bring one to market in record time to ease the global crisis. Several efforts are underway to help make that possible, including the US government's Operation Warp Speed initiative, which has pledged $\$ 10$ billion and aims to develop and deliver 300 million doses of a safe and effective coronavirus vaccine by January 2021. The World Health Organization is also coordinating global efforts to develop a vaccine, with an eye towards delivering two billion doses by the end of 2021 .

The World Health Organization is one of the leaders of a global union known as COVAX; the vaccine is the pillar of the ACT-Accelerator collaboration that is working to accelerate the development and manufacturing of COVID-19 vaccines and ensure that their use is equitable and able to access by different pharmaceutical industries of various regions.

COVAX will allocate vaccines across countries according to a framework developed by a group that includes ethicists, scientists, and other health experts and vetted by WHO's Member States. Under this framework, COVID-19 vaccines will be rolled out in two phases. In the first phase, they will be allocated according to population size to all participating countries at the same time, so as to provide enough vaccine to protect those people at greatest risk of infection and of severe disease along with health workers at risk of transmission. In the second phase of the rollout, as more doses are produced, vaccines should go to groups less at risk of being infected or of suffering badly. COVAX aims to provide at least 2 billion vaccine doses by the end of 2021. Although that is not enough for everyone, it may be enough to end the acute stage of the crisis and put the world on the road to ending the pandemic (Table 5).

\section{COVID-19 vaccine initiatives}

\section{OWS}

Operation Warp Speed is a collaboration of several US government departments including Health and Human Services (HHS) and subagencies; Defense, Agriculture, Energy and Veterans Affairs; and the private sector. OWS has funded JNJ-78436735 (Janssen), mRNA-1273 (Moderna), NVXCoV2373 (Novavax), V590 (Merck/IAVI), V591 (Merck/ Themis), AZD1222 (AstraZeneca/University of Oxford), and the candidate developed by Sanofi and GlaxoSmithKline.

OWS is "part of a broader strategy to accelerate the development, manufacturing, and distribution of COVID-19 vaccines, therapeutics, and diagnostics." Leaders of OWS say they could vaccinate as many as 20 million people by the end of the year and 100 million people by February.

\section{ACTIV}

Within OWS, the US National Institutes of Health (NIH) has partnered with more than 18 biopharmaceutical companies in an initiative called ACTIV. ACTIV aims to fast-track development of drug and vaccine candidates for COVID-19.

\section{COVPN}

The COVID-19 Prevention Trials Network (COVPN) combines clinical trial networks funded by the National Institute of Allergy and Infectious Diseases (NIAID): the HIV Vaccine Trials Network (HVTN), HIV Prevention Trials Network (HPTN), Infectious Diseases Clinical Research Consortium (IDCRC), and the AIDS Clinical Trials Group.

\section{COVAX}

The COVAX initiative, part of the World Health Organization's (WHO) Access to COVID-19 Tools (ACT) Accelerator, is being spearheaded by the Coalition for Epidemic Preparedness Innovations (CEPI); Gavi, the Vaccine Alliance; and WHO. The goal is to work with vaccine manufacturers to offer low-cost COVID-19 vaccines to countries. CEPI's candidates from companies Inovio, Moderna, CureVac, Institut Pasteur/Merck/Themis, AstraZeneca/ University of Oxford, Novavax, University of Hong Kong, Clover Biopharmaceuticals, and University of Queensland/ CSL are part of the COVAX initiative. Further candidates are being evaluated in the COVAX facility from the USA and internationally.

\section{Researches in India}

Indian Council of Medical Research, Department of Health Research, Ministry of Health and Family Welfare, Government of India, has tested many samples of suspected cases all over India. They perform the rapid test for the identification of COVID-19. The ICMR has recommended lopinavir or ritonavir combination therapy for COVID-19confirmed patients. This is based on the observational studies of clinical benefit among patients with SARS-CoV and MERS-CoV, as well as the docking studies conducted by the National Institute of Virology, Pune. The Indian Regulatory Authority, Central Drugs Standard Control Organization, has accorded approval for restricted public health emergency use of this treatment protocol.

Recently on 10 May 2020, ICMR health research body said that India officially entered the race to develop a COVID-19 vaccine. ICMR has partnered with Bharat Biotech International Limited (BBIL) to develop a fully indigenous vaccine for COVID-19. The vaccine will be developed using 
Table 5 Vaccine candidates in development

\begin{tabular}{|c|c|c|c|c|}
\hline Vaccine name & Mechanism & Sponsor & Trial phase & Institution \\
\hline $\mathrm{Ad} 5-\mathrm{nCoV}$ & $\begin{array}{l}\text { Recombinant vaccine } \\
\quad \text { (adenovirus type } 5 \text { vector) }\end{array}$ & CanSino Biologics & Phase III & Tongji Hospital; Wuhan, China \\
\hline Covaxin & Inactivated vaccine & $\begin{array}{l}\text { Bharat Biotech; National } \\
\text { Institute of Virology }\end{array}$ & Phase III & India \\
\hline $\begin{array}{l}\text { JNJ-78436735 (formerly } \\
\text { Ad26.COV2.S) }\end{array}$ & Nonreplicating viral vector & Johnson \& Johnson & Phase III & Johnson \& Johnson \\
\hline NVX-CoV2373 & Nanoparticle vaccine & Novavax & Phase III & Novavax \\
\hline $\begin{array}{l}\text { Bacillus Calmette-Guerin (BCG) } \\
\text { vaccine }\end{array}$ & Live-attenuated vaccine & $\begin{array}{l}\text { University of Melbourne and } \\
\text { Murdoch Children's } \\
\text { Research Institute; Radboud } \\
\text { University Medical Center; } \\
\text { Faustman Lab at } \\
\text { Massachusetts General } \\
\text { Hospital }\end{array}$ & Phase II/III & $\begin{array}{l}\text { University of Melbourne and } \\
\text { Murdoch Children's } \\
\text { Research Institute; Radboud } \\
\text { University Medical Center; } \\
\text { Faustman Lab at } \\
\text { Massachusetts General } \\
\text { Hospital }\end{array}$ \\
\hline INO-4800 & DNA vaccine (plasmid) & Inovio Pharmaceuticals & Phase II/III & $\begin{array}{l}\text { The Center for Pharmaceutical } \\
\text { Research, Kansas City. Mo.; } \\
\text { University of Pennsylvania, } \\
\text { Philadelphia }\end{array}$ \\
\hline VIR-7831 & Plant-based adjuvant vaccine & Medicago; GSK; Dynavax & Phase II/III & Medicago \\
\hline $\mathrm{CVnCoV}$ & mRNA-based vaccine & CureVac & Phase IIb/III & CureVac \\
\hline
\end{tabular}

the virus strain isolated at the ICMR National institute of virology (NIV), Pune. Work on vaccine development has been initiated between two partners. The ICMR-NIV will provide continuous support to BBIL for vaccine development, subsequent animal studies, and clinical evaluation of the candidate vaccine.

CSIR-Institute of Himalayan Bioresource Technology (CSIR-IHBT) Palampur, Himachal Pradesh, has developed a new type of hand sanitizer that contains natural flavor active tea and alcohol. Dr. Sanjay Kumar, Director of IHBT, developed the hand sanitizer and used it as per the guidelines of the World Health Organization (WHO). One of the important things is that chemicals like parabens, triclosan, synthetic fragrance, and phthalates have not been used in this product.

Press release issued stated this technology has been transferred to Palampur-based company M/s A.B. Scientific Solutions for the commercialization of this newly developed hand sanitizer. An agreement has been signed between the CSIR and Institute of Himalayan Bioresource Technology (CSIR-IHBT).

Cellular Molecular Biology (CCMB-CSIR), Hyderabad, has worked on sequencing the whole genome of the COVID-19-infected patient. CSIR-CCMB has prepared the SOP (standard operating procedure) for COVID-19 and getting approval from ICMR. CSIR-CCMB has trained doctors and technical staff carrying out the RT-PCR test (as approved by ICMR) and observing the necessary precautions in handling the patient sample. They generated a video manual on RNA isolation and RT-PCR. This manual is freely available to the doctors, hospitals, and clinics who have received regulatory approval to carry out the test. Approved medical centers may email to director@ccmb.res.in with necessary proof of regulatory approval to avail the resources.

From the Indian Institute of Chemical Biology (IICBCSIR), Kolkata, two scientists in the division, Dr. Subhajit Biswas and Dr. Upasana Ray, have designed a research proposal to find "inhibitors" against the' that will prevent the entry of coronavirus in human cells.

Department of Science \& Technology has funded "Module Innovations," a Pune-based healthcare startup working on point of care diagnostics to build up on its platform technology for rapid diagnosis of diseases to develop a product for detecting COVID-19 with a 10 - to 15 -min test.

The aim of nCoVSENSe test is to detect the IgG and IgM antibodies generated in the human body upon the onset of viral infection and is targeted against the Spike proteins making it specific for COVID-19.

The current confirmatory method of real-time reverse transcription-polymerase chain reaction (RT-PCR) is costly, takes a longer time, and needs trained manpower. This new rapid test will help manage the problem in a more efficient way at a lesser cost.

\section{Conclusion}

The recent COVID-19 outbreak has been considered as a global health emergency. At the global level, the number of positive cases has continued to rise and is currently placed at 75,110,651 confirmed cases of COVID-19, with over 1,680,395 deaths (WHO 2020). This new virus outbreak has challenged the economic, medical, and public health 
infrastructure of several countries. Old age and immunity weaker patients are at the greatest risk of fatality. The rapid spread of the disease needs isolation protocols to prevent further transmission. There is no confirmed medication or vaccine that has been available to control the severe effect of the disease. Most of the researchers, doctors, government institutes and labs, and organizations have been continuously working on the development of a novel drug to control the outbreak.

Acknowledgements I would like to show my warm thank to my lab members and supervisor who supported me at every bit and without whom it was impossible to accomplish the end task.

\section{Declarations}

Conflict of interest There authors declare no competing interests.

\section{References}

Adedeji AO, Severson W, Jonsson C, Singh K, Weiss SR, Sarafianos SG. Novel inhibitors of severe acute respiratory syndrome coronavirus entry that act by three distinct mechanisms. J Virol. 2013;87(14): 8017-28. https://doi.org/10.1128/JVI.00998-13.

Ar Gouilh M, Puechmaille SJ, Diancourt L, Vandenbogaert M, Serra-Cobo J, Lopez Roïg M, et al. SARS-CoV related Betacoronavirus and diverse Alphacoronavirus members found in western old-world. Virology. 2018;517:88-97. https://doi.org/10.1016/j.virol.2018.01.014.

Chan JF, Choi GK, Tsang AK, Tee KM, Lam HY, Yip CC, et al. Development and evaluation of novel real-time reverse transcription-PCR assays with locked nucleic acid probes targeting leader sequences of human-pathogenic coronaviruses. J Clin Microbiol. 2015;53(8):2722-6. https://doi.org/10.1128/JCM. 01224-15.

Chan JF, Kok KH, Zhu Z, Chu H, To KK, Yuan S, et al. Genomic characterization of the 2019 novel human-pathogenic coronavirus isolated from a patient with atypical pneumonia after visiting Wuhan. Emerg Microbes Infect. 2020a;9(1):221-36. https://doi. org/10.1080/22221751.2020.1719902.

Chan JF-W, Yip CC-Y, To KK-W, Tang TH-C, Wong SC-Y, Leung KH, et al. Improved molecular diagnosis of COVID-19 by the novel, highly sensitive and specific COVID-19-RdRp/Hel real-time reverse transcription-polymerase chain reaction assay validated in vitro and with clinical specimens. J Clin Microbiol. 2020;58(5): e00310-20. https://doi.org/10.1128/JCM.00310-20.

Chen N, Zhou M, Dong X, et al. Epidemiological and clinical characteristics of 99 cases of 2019 novel coronavirus pneumonia in Wuhan, China: a descriptive study, Lancet (2020), 10.1016/S0140-6736 (20)30211-7. Novel coronavirus in Wuhan, China. Lancet. 2020;395:497-506.

Chu CM. Role of lopinavir/ritonavir in the treatment of SARS: initial virological and clinical findings. Thorax. 2004;59:252-6.

Chu DKW, Pan Y, Cheng SMS, Hui KPY, Krishnan P, Liu Y, et al. Molecular diagnosis of a novel coronavirus (2019-nCoV) causing an outbreak of pneumonia. Clin Chem. 2020;66:549-55.

Dhama K, Pawaiya RVS, Chakraborty S, Tiwari R, Saminathan M, Verma AK. Coronavirus infection in equines: a review. Asian J Anim Vet Adv. 2014;9(3):164-76. https://doi.org/10.3923/ajava. 2014.164.176.
Dhama K, Sharun K, Tiwari R, Dadar M, Malik YS, Singh KP, et al. COVID-19, an emerging coronavirus infection: advances and prospects in designing and developing vaccines, immunotherapeutics and therapeutics. Hum Vaccines and Immunother. 2020;16:12328. https://doi.org/10.1080/21645515.2020.1735227.

Elsevier, Novel Coronavirus Information Center. (2020) https://www. elsevier.com/connect/coronavirus-information-center.

Falzarano D, de Wit E, Rasmussen AL, Feldmann F, Okumura A, Scott $\mathrm{DP}$, et al. Treatment with interferon- $\alpha 2 \mathrm{~b}$ and ribavirin improves outcome in MERS-CoV1940 infected rhesus macaques. Nat Med. 2013;19(10):1313-7. https://doi.org/10.1038/nm.3362.

Fan Y, Zhao K, Shi ZL, Zhou P. Bat coronaviruses in China. Viruses. 2019;11(3):210. https://doi.org/10.3390/v11030210c.

Fehr AR, Perlman S. Coronaviruses: an overview of their replication and pathogenesis. Methods Mol Biol. 2015;1282:1-23. https://doi.org/ 10.1007/978-1-4939-2438-7_1.

Gao Y, Yan L, Huang Y, Liu F, Zhao Y, Cao L, et al. The structure of the COVID-19 virus polymerase essential for viral replication provides a basis for the design of new antiviral drugs. Science. 2020;368(6492)779-82. https://doi.org/10.1126/science.abb7498.

Gomez DE, Arroyo LG, Poljak Z, Viel L, Weese JS. Detection of bovine coronavirus in healthy and diarrheic dairy calves. J Vet Intern Med. 2017;31(6):1884-91.

HM Government, Novel coronavirus: guidance for primary care. (2020). https:// www.gov.uk/government/publications/wn-cov-guidancefor-primary-care. HM Government, 2019-nCoV Acute Respiratory Disease: Guidance for Clinical Diagnostic Laboratories, (2020) https:/www.gov.uk/government/publications/ wuhan-novelcoronavirus-guidance-for-clinical-diagnostic-laboratories.

Huang P, Wang H, Cao Z, Jin H, Chi H, Zhao J, et al. A rapid and specific assay for the detection of MERS-CoV. Front Microbiol. 2018;9:1101.

Huang C, Wang Y, Li X, Ren L, Zhao J, Hu Y, et al. Clinical features of patients infected with 2019 novel coronavirus in Wuhan, China. Lancet. 2020a;395:497-506.

Huang P, Liu T, Huang L, Liu H, Lei M, Xu W, et al. Use of chest CT in combination with negative RT-PCR assay for the 2019 novel coronavirus but high clinical suspicion. Radiology. 2020b;295:22-3. https://doi.org/10.1148/radiol.2020200330.

Jin YH, Cai L, Cheng ZS, et al. A rapid advice guideline for the diagnosis and treatment of 2019 novel coronavirus [2019-nCoV] infected pneumonia [standard version]. Mil Med Res. 2020;7:4.

Kim TW, Lee JH, Hung CF, Peng S, Roden R, Wang MC, Viscidi R, Tsai YC, He L, Chen PJ, Boyd DA, Wu TC. Generation and characterization of DNA vaccines targeting the nucleocapsid protein of severe acute respiratory syndrome coronavirus. J Virol. 2004;78: 4638-45.

Kritas SK, Ronconi G, Caraffa A, Gallenga CE, Ross R, Conti P. Mast cells contribute to coronavirus-induced inflammation: new antiinflammatory strategy. J Biol Regul Homeost Agents. 2020;34(1). https://doi.org/10.23812/20-Editorial-Kritas.

Kui L, Fang YY, Deng Y, et al. Clinical characteristics of novel coronavirus cases in tertiary hospitals in Hubei Province. Chin Med J. $2020 ; 1$.

Lai MMC, Holmes KV. Coronaviridae: the viruses and their replication fields. In: Knipe BN, Howley DM, PM, editors. Fields virology, vol. 1163. Philadephia: Lippincott-Raven; 2001. p. 1185.

Lee SH, Baek YH, Kim Y-H, Choi Y-K, Song M-S, Ahn J-Y. One-pot reverse transcriptional loop-mediated isothermal amplification (RTLAMP) for detecting MERS-CoV. Front Microbiol. 2017;7: 2166.https://doi.org/10.3389/fmicb.2016.02166.

Li H, Wang YM, Xu JY, Cao B. 2020a. Potential antiviral therapeutics for 2019 novel 1949 coronavirus. Zhonghua Jie He He Hu Xi ZaZhi 43(00): E002-E002. doi: 1950 https://doi.org/10.3760/cma.j.issn. 1001-0939.2020.0002. 
Li G, Fan Y, Lai Y, Han T, Li Z, Zhou P, et al. Coronavirus infections and immune responses. J Med Virol. 2020b. https://doi.org/10.1002/ jmv.25685.10.1002/jmv.25685.

Li B, Si HR, Zhu Y, Yang XL, Anderson DE, Shi ZL, et al. Discovery of bat coronaviruses through surveillance and probe capture-based next1442 generation sequencing. mSphere. 2020d;5(1):e00807-19. https://doi.org/10.1128/mSphere.00807-19.

Liu J, Liu S. The management of coronavirus disease 2019 (COVID-19). J Med Virol. 2020;92:1484-90. https://doi.org/10.1002/jmv.25965.

$\mathrm{Lu} \mathrm{H}$. Drug treatment options for the 2019-new coronavirus (2019nCoV). Biosci Trends. 2020;14:69-71. https://doi.org/10.5582/bst. 2020.01020 .

Lu L, Liu Q, Du L, Jiang S. Middle East respiratory syndrome coronavirus (MERS-CoV): challenges in identifying its source and controlling its spread. Microbes Infect. 2013;15(8-9):625-9. https://doi.org/ 10.1016/j.micinf.2013.06.003.

$\mathrm{Lu} \mathrm{H}$, Stratton CW, Tang Y. Outbreak of pneumonia of unknown etiology in Wuhan China: the mystery and the miracle. J Med Virol. 2020;25678.

Luo X, Zhou GZ, Zhang Y. Coronaviruses and gastrointestinal diseases. Military Med Res. 2020;7:49. https://doi.org/10.1186/s40779-02000279-z.

MacLachlan NJ, Dubovi EJ. In: MacLachlan NJ, Dubovi EJ, editors. Fenner's veterinary virology. Fifth ed: Academic Press; 2017. p. 393-413.

Monchatre-Leroy E, Boue F, Boucher JM, Renault C, Moutou F, Ar Gouilh $\mathrm{M}$, et al. Identification of alpha and beta coronavirus in wildlife species in France: bats, rodents, rabbits, and hedgehogs. Viruses. 2017;9(12):364. https://doi.org/10.3390/v9120364.

Munster VJ, Koopmans M, van Doremalen N, van Riel D, de Wit E. A novel coronavirus emerging in China-key questions for impact assessment. N Engl J Med. 2020. https://doi.org/10.1056/ NEJMp2000929.

Pillaiyar T, Meenakshisundaram S, Manickam M. Recent discovery and development of inhibitors targeting coronaviruses. Drug Discov Today. 2020;S1359-6446(20)30041-6. https://doi.org/10.1016/j. drudis.2020.01.015.

Public Health England, Coronavirus (COVID-19). Latest Information and Advice. 2020. https://www.gov.uk/guidance/wuhan-novelcoronavirus-information-forthe-public\#history.

Rhodes A, Evans LE, Alhazzani W, et al. Surviving sepsis campaign: international guidelines for management of sepsis and septic shock. Intensive Care Med. 2016;43:304-77.

Rodriguez-Morales AJ, Bonilla-Aldana DK, Balbin-Ramon GJ, Rabaan AA, Sah R, Paniz-Mondolfi A, et al. History is repeating itself: probable zoonotic spillover as the cause of the 2019 novel coronavirus epidemic. Infez Med. 2020;28(1):3-5.

Rosjo H, Varpula M, Hagve TA, Karlsson S, Ruokonen E, Pettila V, et al. Circulating high sensitivity troponin $\mathrm{T}$ in severe sepsis and septic shock: distribution, associated factors, and relation to outcome. Intensive Care Med. 2011;37:77-85.

Schultz MJ, Dunser MW, Dondorp AM, et al. Current challenges in the management of sepsis in ICUs in resource-poor settings and suggestions for the future. Intensive Care Med. 2017;43:612-24.
Sheahan TP, Sims AC, Leist SR, Schäfer A, Won J, Brown AJ, et al. Comparative therapeutic efficacy of remdesivir and combination lopinavir, ritonavir, and interferon 1334 beta against MERS-CoV. Nat Commun. 2020;11(1):222. https://doi.org/10.1038/s41467-01913940-6.

Su S, Wong G, Shi W, Liu J, Lai ACK, Zhou J, et al. Epidemiology, genetic recombination, and pathogenesis of coronaviruses. Trends Microbiol. 2016;24(6):490-502. https://doi.org/10.1016/j.tim.2016. 03.003 .

Wang D, Hu B, Hu C, Zhu F, Liu X, Zhang J, et al. Clinical characteristics of 138 hospitalized patients with 2019 novel coronavirusinfected pneumonia in Wuhan, China. J Am Med Assoc. 2020a:323:1061-9. https://doi.org/10.1001/jama.2020.1585.

Wang C, Horby PW, Hayden FG, Gao GF. A novel coronavirus outbreak of global health concern. Lancet. 2020c. https://oi.org/10.1016/ S0140-6736(20)30185-9.

Weiss SR, Leibowitz JL. Coronavirus pathogenesis. Adv Virus Res. 2011;81:85-164. https://doi.org/10.1016/B978-0-12-385885-6. 00009-2.

Wellcome, Sharing Research Data and Findings Relevant to the Novel Coronavirus (nCoV) Outbreak, (2020).

WHO. 2003. World Health Organization. Consensus document on the epidemiology of severe acute respiratory syndrome (SARS). Available online: https://www.who.int/csr/sars/en/WHOconsensus. pdf (accessed on 29 January 2020).

Woo PC, Lau SK, Lam CS, Lau CC, Tsang AK, Lau JH, et al. Discovery of seven novel mammalian and avian coronaviruses in the genus deltacoronavirus supports bat coronaviruses as the gene source of alphacoronavirus and betacoronavirus and avian coronaviruses as the gene source of gammacoronavirus and deltacoronavirus. J Virol. 2012;86(7):3995-4008. https://doi.org/10.1128/JVI.06540-11.

World Health Organization. Pocket book of Hospital Care for Children: guidelines for the Management of Common Childhood Illnesses. 2013.

World Health Organization. WHO Global Epidemiological Surveillance Standards for Influenza. 2014

World Health Organization. Novel Coronavirus (2019-nCoV), Situation Report - 122020.

Wu P, Hao X, Lau EHY, Wong JY, Leung KSM, Wu JT, et al. Real-time tentative assessment of the epidemiological characteristics of novel coronavirus infections in Wuhan, China, as at 22 January 2020. Euro Surveill. 2020;25:2000044.

Zhang XM, Herbst W, Kousoulas KG, Storz J. Biological and genetic characterization of a hemagglutinating coronavirus isolated from a diarrhoeic child. J Med Virol. 1994;44(2):152-61.

Zhang L, Shen FM, Chen F, Lin Z. Origin and evolution of the 2019 novel coronavirus [published online ahead of print, 2020 Feb 3]. Clin Infect Dis. 2020:ciaa112. https://doi.org/10.1093/cid/ciaa112.

Zhou P, Yang XL, Wang XG, et al. A pneumonia outbreak associated with a new coronavirus of probable bat origin. Nature. 2020;579: $270-3$.

Publisher's note Springer Nature remains neutral with regard to jurisdictional claims in published maps and institutional affiliations. 